\title{
Improving the Construction Industry Quality Using the Seven Basic Quality Control Tools
}

\author{
Mohamed Abdel-Hamid', Hanaa Mohamed Abdelhaleem² \\ ${ }^{1}$ Civil Engineering Department, Faculty of Engineering at Shobra, Benha University, Benha, Egypt \\ ${ }^{2}$ Civil Engineering Department, Delta Higher Institute for Engineering and Technology, Mansoura, Egypt \\ Email: mhamid01@gmail.com
}

How to cite this paper: Abdel-Hamid, M. and Abdelhaleem, H.M. (2019) Improving the Construction Industry Quality Using the Seven Basic Quality Control Tools. Journal of Minerals and Materials Characterization and Engineering, 7, 412-420. https://doi.org/10.4236/jmmce.2019.76028

Received: October 1, 2019

Accepted: November 5, 2019

Published: November 8, 2019

Copyright $\odot 2019$ by author(s) and Scientific Research Publishing Inc. This work is licensed under the Creative Commons Attribution International License (CC BY 4.0).

http://creativecommons.org/licenses/by/4.0/

\begin{abstract}
The organizations used quality tools to develop their processes and gain satisfaction from the customers. The main objective of this study is to develop levels of quality in the construction industry through the use of the seven basic quality control tools. Such tools are extremely crucial tools which are used worldwide in the industries for continual improvement. The seven basic quality tools are Check Sheet, Histogram, Pareto Chart, Fishbone Diagram, Control Chart, Flowchart and Scatter Diagram. They were implemented in various steps of the process in order to define the problems, measure its impacts, find out its root causes and solve these problems to ensure the production of non-defective items. The study shows how the seven basic tools of quality are very useful and effective in identifying and removal of defects from the manufacturing process. These tools are helpful in every stage of the defect removal process. This study was conducted on Cleopatra Group Company. This company succeeded to serve the public and private projects in the Egyptian construction sectors.
\end{abstract}

\section{Keywords}

Quality Improvement, Seven Basic Quality Control Tools, Construction Industry

\section{Introduction}

Being a continuous process, quality improvement seized the use of the quality control tools. Quality is considered an effective factor in today's competitive environment. Decreasing the wastage, reaching the high expectations of the customers, reducing the costs, taking various steps towards improvement and achieving the development of the products are the main results of the imple- 
mentation of the seven basic quality control tools. The main aim of this study is to investigate the successful application of the seven basic quality control tools in the construction industry. A research was carried out in a Cleopatra Group Company. Cleopatra Group is able to meet all the requirements of the ceramic industry of porcelain, floor tiles, wall tiles and bathroom accessories. In 1995, Ceramic Cleopatra Group was awarded ISO 9001 certification, which is followed by the UNIDO Prize in 1997. The company also acquired the rights to develop an industrial zone in the Suez economic Zone through 1998. Finally, it won the award for its excellence and the ISO 14001 certification. According to ISO 9001:2008, organizations ought to guarantee that the customer requirements are determined to ensure their satisfaction [1]. Thus, organizations need to enhance their processes, and for that, they use a set of practices, which include various tools and techniques, especially, the seven basic quality tools. Relatively, quality, productivity and cost of operation rely on each other [2]. The fundamental objective of quality management is the customer satisfaction with the delivery of the defect free products at the least cost. In 2013, a case study was directed to decrease the scrap in the car mechanical production systems using quality control tools [3]. It brings about enormous sparing in the cost to the organization. Another study, which was conducted in steel industry, helped to diminish the greater part of the issues identified with the quality [4]. The seven basic quality control tools can help an organization in problems solving and process improvements. The first master who proposed seven basic tools was Dr. Kaoru Ishikawa at (1968), by writing a book entitled "Gemba no QC Shuho" that was aimed managing quality through systems and practices for the Japanese firms [5]. These seven basic quality control tools are: Check Sheet, Histogram, Pareto Chart, Fishbone Diagram, Control Chart, Flowchart and Scatter Diagram. The following sections explain the detailed use of these tools and its application on the case study.

The Check Sheet is sometimes called a tally sheet. It is a basic form with specific arrangements that can help the user to record the data. Data are gathered and organized on the check sheet to record the frequency of particular occasions during a data collection period. It sets up a reliable, compelling and conservative approach that can be applied in the auditing of quality assurance for checking on and following the steps in particular processes. In addition, it helps the user to organize the data for the later usage [5] [6]. The fundamental favorable circumstances of the check sheet are being effortless to apply, comprehend results as well as making a reasonable picture of the organization state. It is a producer and an intense tool to identify frequently problems and issues, but it doesn't have successful capacity to analyze the quality issue in the workplace. Table 1 depicts a check sheet that can be used for collecting data during the production process in the selected case study and showing the repeated defects and their types through 30 workdays. As shown in the table, the Cracks Sides were the most repeated defects as they happened 4851 times, and then they are followed 
by the Dimension error which was repeated 2242 times, while Broken Edges were the least repeated defects as they happened 296 times. Moreover, the table shows that the second day has encountered the greatest number of defects which were 1363. These defects were discovered by the Control Chart and to clarify the results, we use a Histogram and Pareto Chart.

Table 1. Check sheet for reasons of low grades and refuse the products.

\begin{tabular}{|c|c|c|c|c|c|c|c|c|c|c|c|c|c|c|c|c|c|c|c|c|c|c|c|c|c|c|c|c|c|c|c|}
\hline Defects/Days & 1 & 2 & 3 & 4 & 5 & 6 & 7 & 8 & 9 & 10 & 11 & 12 & 13 & 14 & 15 & 16 & 17 & 18 & 19 & 20 & 21 & 22 & 23 & 24 & 25 & 26 & 27 & 28 & 29 & 30 & Sum \\
\hline Pin holes & 18 & 26 & 19 & 26 & 17 & 25 & 20 & 21 & 23 & 31 & 26 & 32 & 33 & 21 & 22 & 22 & 19 & 21 & 22 & 33 & 26 & 28 & 31 & 32 & 29 & 30 & 32 & 33 & 31 & 33 & 782 \\
\hline $\begin{array}{l}\text { Cracks } \\
\text { corner }\end{array}$ & 33 & 48 & 36 & 49 & 32 & 47 & 39 & 29 & 31 & 39 & 34 & 40 & 41 & 29 & 30 & 30 & 27 & 29 & 30 & 41 & 34 & 36 & 39 & 40 & 37 & 38 & 40 & 41 & 39 & 41 & 1099 \\
\hline Cracks side & 332 & 450 & 344 & 460 & 356 & 91 & 140 & 110 & 112 & 120 & 115 & 121 & 122 & 110 & 111 & 111 & 108 & 110 & 111 & 122 & 115 & 117 & 120 & 121 & 118 & 119 & 121 & 122 & 120 & 122 & 4851 \\
\hline $\begin{array}{l}\text { Cracks } \\
\text { middle }\end{array}$ & 31 & 43 & 33 & 44 & 34 & 8 & 38 & 40 & 42 & 50 & 45 & 51 & 52 & 40 & 41 & 41 & 38 & 40 & 41 & 52 & 45 & 47 & 50 & 51 & 48 & 49 & 51 & 52 & 50 & 52 & 1299 \\
\hline $\begin{array}{l}\text { Cracking } \\
\text { under glaze }\end{array}$ & 7 & 10 & 7 & 9 & 6 & 3 & 6 & 7 & 9 & 17 & 12 & 18 & 19 & 7 & 8 & 8 & 5 & 7 & 8 & 19 & 12 & 14 & 17 & 18 & 15 & 16 & 18 & 19 & 17 & 19 & 357 \\
\hline $\begin{array}{l}\text { Planarity } \\
\text { convex }\end{array}$ & 18 & 26 & 18 & 23 & 15 & 7 & 17 & 9 & 11 & 19 & 14 & 20 & 21 & 9 & 10 & 10 & 7 & 9 & 10 & 21 & 14 & 16 & 19 & 20 & 17 & 18 & 20 & 21 & 19 & 21 & 479 \\
\hline $\begin{array}{l}\text { Planarity } \\
\text { concave }\end{array}$ & 39 & 50 & 34 & 43 & 28 & 13 & 30 & 27 & 29 & 37 & 32 & 38 & 39 & 27 & 28 & 28 & 25 & 27 & 28 & 39 & 32 & 34 & 37 & 38 & 35 & 36 & 38 & 39 & 37 & 39 & 1006 \\
\hline Pits & 38 & 49 & 32 & 40 & 24 & 10 & 25 & 22 & 24 & 32 & 27 & 33 & 34 & 22 & 23 & 23 & 20 & 22 & 23 & 34 & 27 & 29 & 32 & 33 & 30 & 31 & 33 & 34 & 32 & 34 & 872 \\
\hline Dust & 36 & 43 & 28 & 35 & 23 & 9 & 27 & 24 & 26 & 34 & 29 & 35 & 36 & 24 & 25 & 25 & 22 & 24 & 25 & 36 & 29 & 31 & 34 & 35 & 32 & 33 & 35 & 36 & 34 & 36 & 901 \\
\hline $\begin{array}{l}\text { Dust under } \\
\text { glaze }\end{array}$ & 39 & 42 & 27 & 33 & 19 & 6 & 17 & 13 & 15 & 23 & 18 & 24 & 25 & 13 & 14 & 14 & 11 & 13 & 14 & 25 & 18 & 20 & 23 & 24 & 21 & 22 & 24 & 25 & 23 & 25 & 630 \\
\hline Black point & 27 & 29 & 18 & 22 & 18 & 5 & 15 & 12 & 14 & 22 & 17 & 23 & 24 & 12 & 13 & 13 & 10 & 12 & 13 & 24 & 17 & 19 & 22 & 23 & 20 & 21 & 23 & 24 & 22 & 24 & 558 \\
\hline Other point & 23 & 27 & 16 & 19 & 31 & 8 & 25 & 30 & 32 & 40 & 35 & 41 & 42 & 30 & 31 & 31 & 28 & 30 & 31 & 42 & 35 & 37 & 40 & 41 & 38 & 39 & 41 & 42 & 40 & 42 & 987 \\
\hline Spots & 17 & 19 & 11 & 13 & 21 & 5 & 16 & 18 & 20 & 28 & 23 & 29 & 30 & 18 & 19 & 19 & 16 & 18 & 19 & 30 & 23 & 25 & 28 & 29 & 26 & 27 & 29 & 30 & 28 & 30 & 664 \\
\hline Kiln defect & 32 & 36 & 20 & 23 & 37 & 9 & 28 & 29 & 31 & 39 & 34 & 40 & 41 & 29 & 30 & 30 & 27 & 29 & 30 & 41 & 34 & 36 & 39 & 40 & 37 & 38 & 40 & 41 & 39 & 41 & 1000 \\
\hline Grains & 14 & 16 & 8 & 9 & 19 & 2 & 14 & 15 & 17 & 25 & 20 & 26 & 27 & 15 & 16 & 16 & 13 & 15 & 16 & 27 & 20 & 22 & 25 & 26 & 23 & 24 & 26 & 27 & 25 & 27 & 575 \\
\hline $\begin{array}{l}\text { Broken } \\
\text { corner }\end{array}$ & 39 & 44 & 21 & 16 & 40 & 22 & 24 & 22 & 24 & 32 & 27 & 33 & 34 & 22 & 23 & 23 & 20 & 22 & 23 & 34 & 27 & 29 & 32 & 33 & 30 & 31 & 33 & 34 & 32 & 34 & 860 \\
\hline Broken edge & 12 & 13 & 6 & 4 & 10 & 6 & 5 & 4 & 6 & 14 & 9 & 15 & 16 & 4 & 5 & 5 & 2 & 4 & 5 & 16 & 9 & 11 & 14 & 15 & 12 & 13 & 15 & 16 & 14 & 16 & 296 \\
\hline Application & 37 & 41 & 18 & 12 & 23 & 23 & 9 & 6 & 8 & 16 & 11 & 17 & 18 & 6 & 7 & 7 & 4 & 6 & 7 & 18 & 11 & 13 & 16 & 17 & 14 & 15 & 17 & 18 & 16 & 18 & 449 \\
\hline Calibration & 24 & 26 & 11 & 7 & 11 & 22 & 13 & 3 & 5 & 13 & 8 & 14 & 15 & 3 & 4 & 4 & 1 & 3 & 4 & 15 & 8 & 10 & 13 & 14 & 11 & 12 & 14 & 15 & 13 & 15 & 331 \\
\hline Broken angel & 27 & 29 & 12 & 7 & 23 & 11 & 10 & 8 & 10 & 18 & 13 & 19 & 20 & 8 & 9 & 9 & 6 & 8 & 9 & 20 & 13 & 15 & 18 & 19 & 16 & 17 & 19 & 20 & 18 & 20 & 451 \\
\hline Peeling glaze & 36 & 38 & 15 & 8 & 29 & 25 & 12 & 9 & 11 & 19 & 14 & 20 & 21 & 9 & 10 & 10 & 7 & 9 & 10 & 21 & 14 & 16 & 19 & 20 & 17 & 18 & 20 & 21 & 19 & 21 & 518 \\
\hline Rectangularity & 52 & 54 & 21 & 11 & 44 & 34 & 18 & 13 & 15 & 23 & 18 & 24 & 25 & 13 & 14 & 14 & 11 & 13 & 14 & 25 & 18 & 20 & 23 & 24 & 21 & 22 & 24 & 25 & 23 & 25 & 681 \\
\hline $\begin{array}{l}\text { Squaring } \\
\text { defect }\end{array}$ & 24 & 28 & 10 & 5 & 26 & 12 & 13 & 11 & 13 & 21 & 16 & 22 & 23 & 11 & 12 & 12 & 9 & 11 & 12 & 23 & 16 & 18 & 21 & 22 & 19 & 20 & 22 & 23 & 21 & 23 & 519 \\
\hline $\begin{array}{l}\text { Polishing } \\
\text { defect }\end{array}$ & 32 & 36 & 12 & 6 & 33 & 19 & 15 & 13 & 15 & 23 & 18 & 24 & 25 & 13 & 14 & 14 & 11 & 13 & 14 & 25 & 18 & 20 & 23 & 24 & 21 & 22 & 24 & 25 & 23 & 25 & 600 \\
\hline Sub polishing & 6 & 7 & 2 & 3 & 16 & 8 & 19 & 14 & 16 & 24 & 19 & 25 & 26 & 14 & 15 & 15 & 12 & 14 & 15 & 26 & 19 & 21 & 24 & 25 & 22 & 23 & 25 & 26 & 24 & 26 & 531 \\
\hline Sum & 1107 & 71363 & 848 & 988 & 104 & 4450 & 677 & 586 & 640 & 856 & 721 & 883 & 910 & 586 & 613 & 613 & 532 & 586 & 613 & 910 & 721 & 775 & 856 & 883 & 802 & 829 & 883 & 910 & 856 & 910 & 23,951 \\
\hline
\end{tabular}


The Histogram is considered an irreplaceable tool to show the distribution frequency of the variables' values which were observed. It is one of the types of the bar chart which describes the attribute and variable data on a specific research and clarifies the data distribution and its variation in the process. Moreover, it is considered a helping hand for the identification of the underlying distribution of the variable being studied [5] [7]. In order to be easily used and understood by the operation process's workers, the Histogram has to be appropriately and professionally designed. Figure 1 shows the relation between defect type and defect frequency using Histogram in one manufacturing process which were represented in Table 1.

Pareto Chart is a type of a Histogram as well as a Bar chart. Its idea was first introduced by the Italian economist, Pareto, in the 19th century [8]. He took a note that $80 \%$ of the wealth was owned by only $20 \%$ of the population. As a result, the graph was established by Juran in (1950). It is a statistical technique in decision-making used for the selection of a limited number of tasks that produce a significant overall effect. It shows the relative importance of the variables and arranges them in a descending order, according to their priorities from the left of the chart to its right side [8]. It gives a way for searching concerning quality development, improving efficiency, wastage materials, energy saving and cost reductions [5] [6] [9]. Figure 2 shows the Pareto chart that has the values of the defects, which were taken from Figure 1 arranged in a descending order and the calculated cumulative percentages with their drawn curve. Using the " $80 \%$ and $20 \%$ " rule, a line is drawn from the $80 \%$ value and intersects with the curve at a corresponding value which is very informative value. The defects after this value are ignored, while the defects before this value, which are Rectangularity, Polishing defect, Spots, Other point, Kiln defect, Grains, Dimension error, Broken corner, Pits, Dust, Dust under glaze, Planarity concave, Cracks corner, Cracks side, Cracks middle and Pin hole, are used in the study of the root causes of the problem, using the Fishbone Diagram.

Fishbone Diagram is one of the basic quality tools, which is also called an Ishikawa diagram, owing to its developer Dr. Kaoru Ishikawa (1943), and it is called the Cause and effect diagram, as it shows the relationship between all the factors that leads to the given situation [8]. Moreover, it is called the Fishbone diagram because of its resemblance to a fish skeleton. Systematically, it identifies major causes and breaks them down into sub-causes and further sub-divisions in order to investigate, analyze and solve the root causes that, initially, led to the problem. Such a tool aids to help the organization in managing and handling the possible causes of the problem [8]. In addition, such tool bridges the chasm between the organization and the most affecting causes, allows a perfect understanding of the problem and helps in studying each cause [5]. Tile is considered as a low grade owing to its defects then; a Fishbone diagram is used to know the reasons why it is defected. As indicated in Figure 3, the categories of the course are four elements, which are the main causes of cracks side defect. Finally, the potential causes are indicated by other arrows entering the main causes' arrow [10]. 
Control Chart is the most statistically complicated tool for managing the quality [6]. It is also called Shewhart control chart owing to its developer Walter A. Shewhart (1920s) at the bell telephone laboratories. Moreover, it is called the process-behavior charts as it determines the state of control. In addition, it is one of the run charts as it clarifies the amount of variation in the process according to time order as well as shows how the process is going on. Statistically and according to historical data, it shows whether there is a problem with the quality or not by having a central line for the mean, upper line indicating the upper control limit and lower line indicating the lower control limit. The samplings that are not between UCL and LCL are out of control, while those samplings that are among them have no problem.

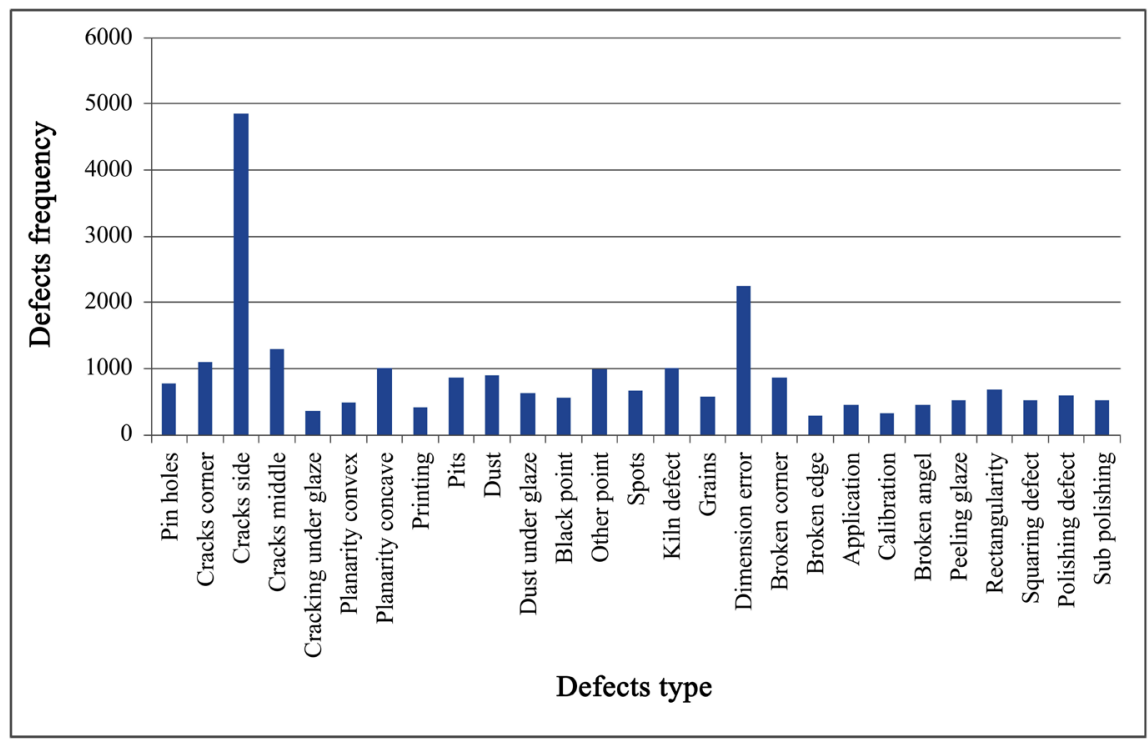

Figure 1. Histogram of the defects frequency.

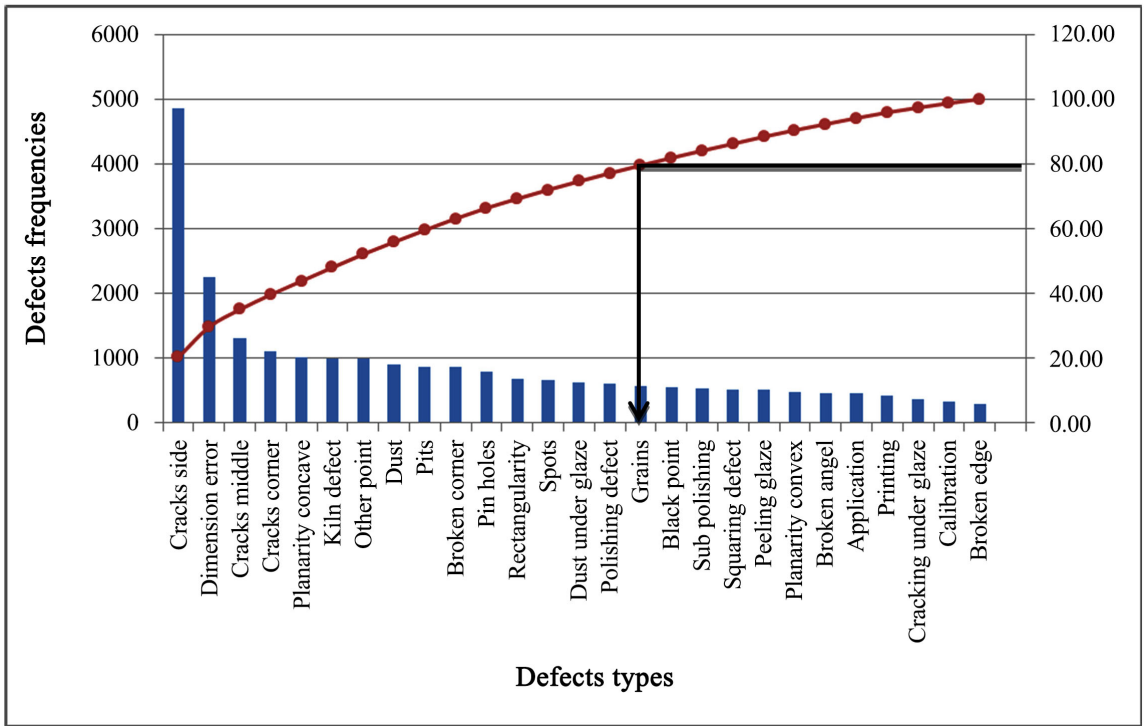

Figure 2. Pareto chart of the frequency of defects. 


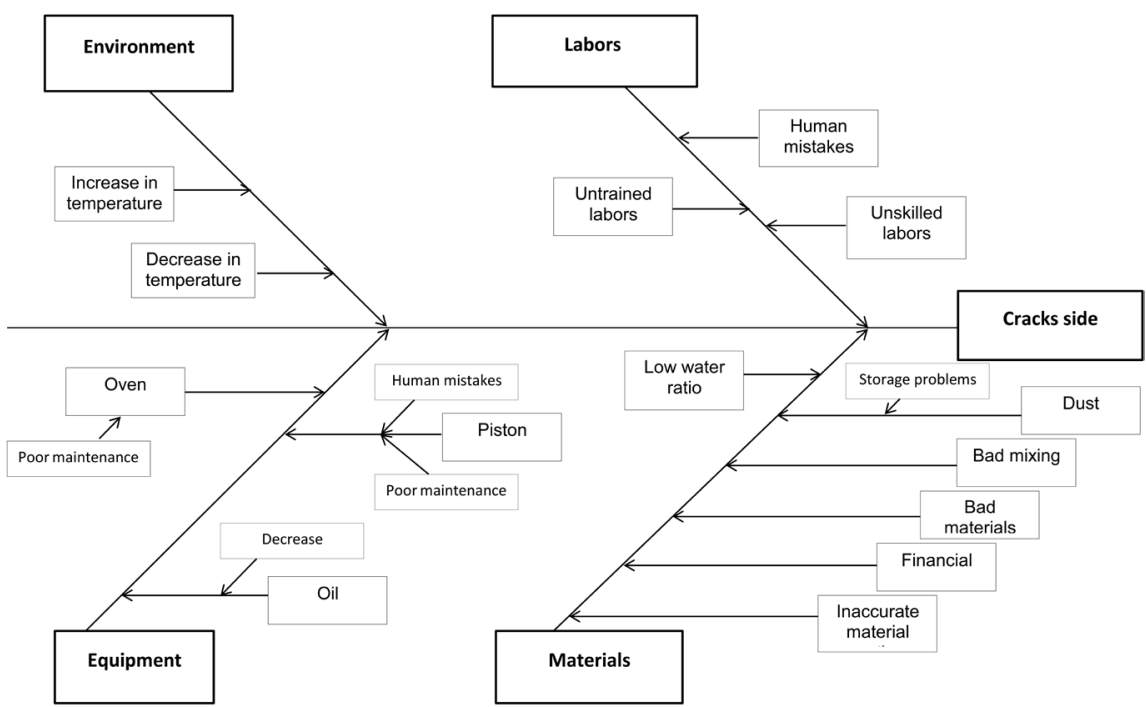

Figure 3. Fishbone Diagram of product defects.

Alongside this, the chart estimates the borders of the process quality and help in decreasing the defects and variations of the processes [5]. Finally, this tool is of a great avail to the construction industry as it saves costs by controlling quality instead of spending money on selling default products, which will certainly result in unsatisfied customers [8]. A control chart shows also specification limits that the area, on either side of the centerline, or mean, of data plotted on a control chart that meets the customer's requirements for a product or service. This area may be greater than or less than the area defined by the control limits. The data used in the control chart Figure 4 and in Table 2 represent the example of Dimension error defects and show the points that are in and out of control.

Flowchart is a formalized graphic representation that contains inputs, activities, decision points and outputs for the aim of representing the main objective of the process. It is one of the problem solving tools which is a visual representation of the sequence of steps and decisions needed to perform a process. Moreover, it helps to study, plan, improve and communicate complex processes in a clear way to handle the defects and the problems of the process as shown in Figure 5. Also, the flow chart shows the process from start to end and the process will be stopped due to any product defect.

Scatter Diagram is a powerful tool to draw the distribution of information in two dimensions, which helps to detect and analyze a pattern relationship between two qualities and compliance variables, as an independent variable and a dependent variable, understand if there is a relationship between them and the relationship kind. The shape of the scatter diagram often shows the degree and direction of the relationship between two variables, and the correlation may reveal the causes of a problem. Scatter diagrams are very useful in regression modeling [6] [11].

The scatter diagram can indicate the correlations between the two variables 
which can be: 1) Positive correlation; 2) Negative correlation, and 3) No correlation, as demonstrated in Table 3 and Figure 6. In this figure, there is no correlation between Cracks side and temperature.

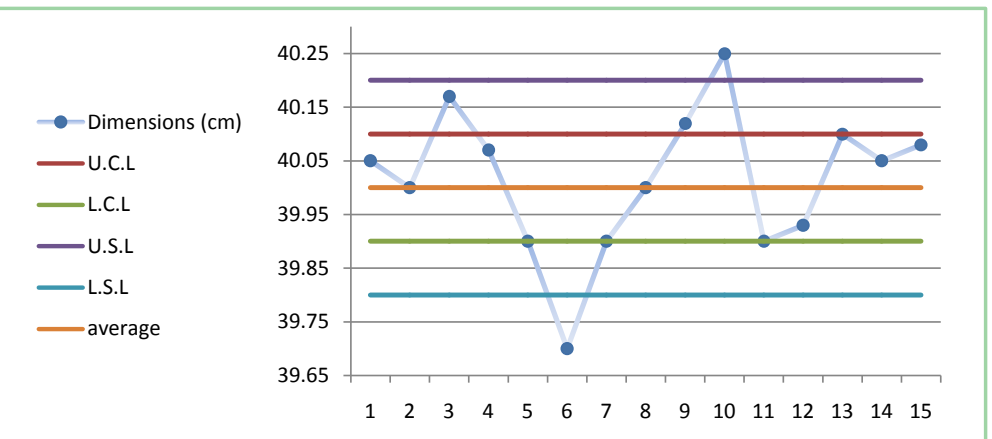

Figure 4. Control chart for Dimension error defects.

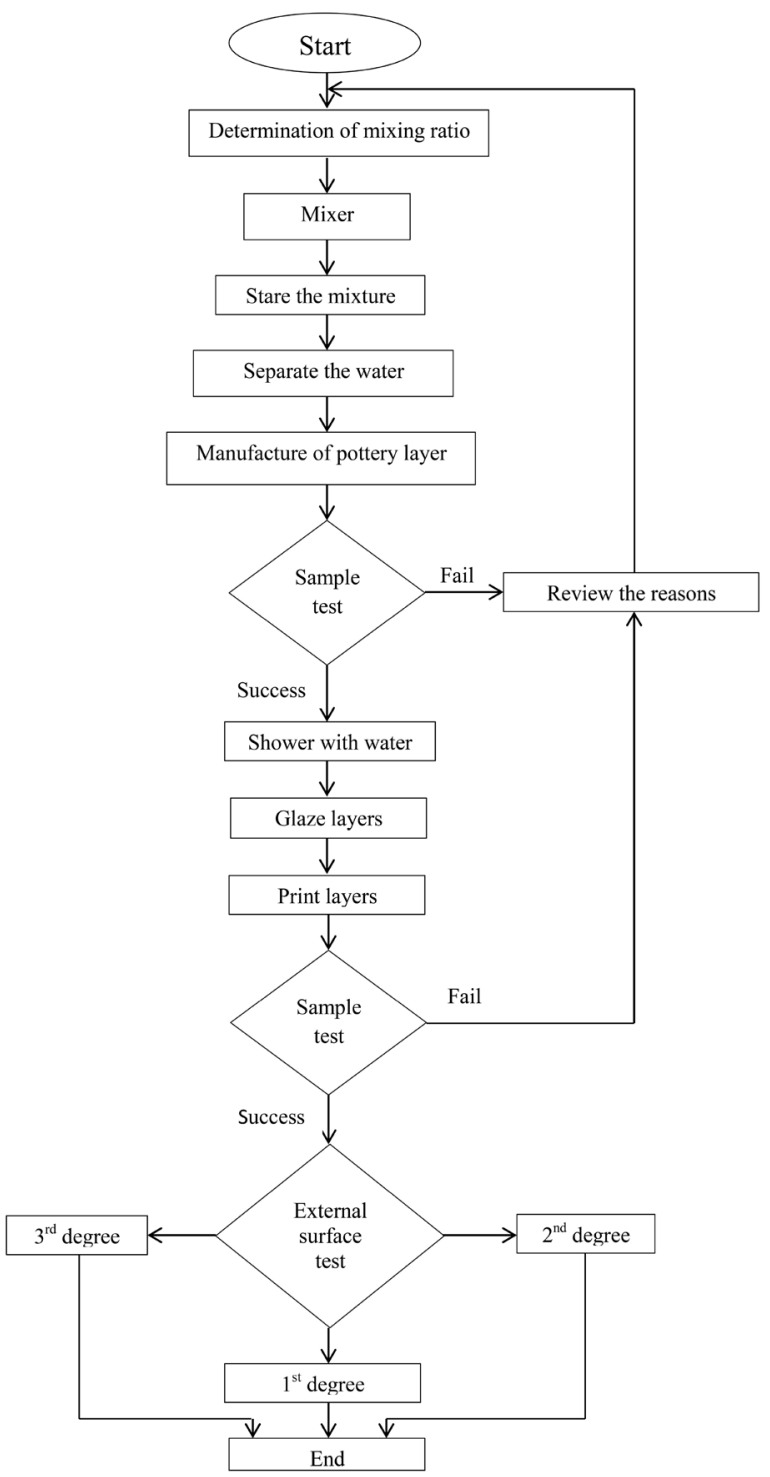

Figure 5. Control chart. 


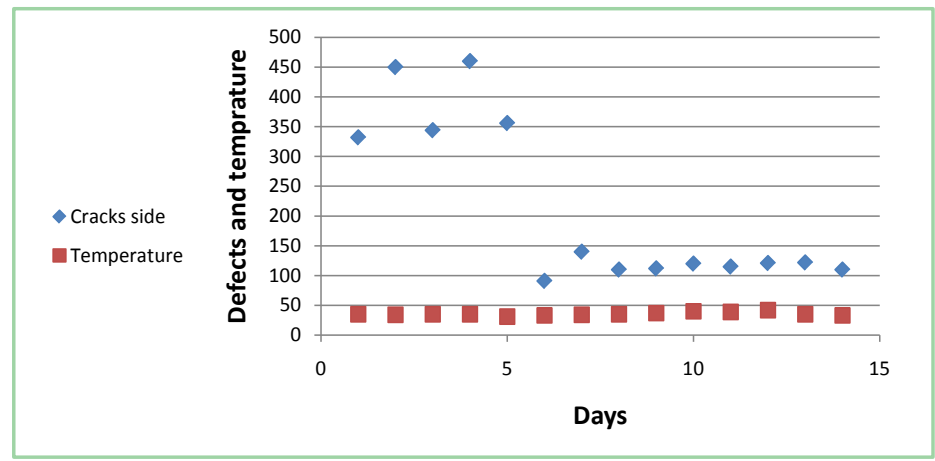

Figure 6. Scatter diagram (relation between Cracks side and temperature).

Table 2. Control chart for Dimension error defects.

\begin{tabular}{|c|c|c|c|c|c|c|c|c|c|c|c|c|c|c|c|}
\hline Dimensions $(\mathrm{cm})$ & 40.05 & 40 & 40.17 & 40.07 & 39.9 & 39.7 & 39.9 & 40 & 40.12 & 40.25 & 39.9 & 39.93 & 40.1 & 40.05 & 40.08 \\
\hline U.C.L & 40.1 & 40.1 & 40.1 & 40.1 & 40.1 & 40.1 & 40.1 & 40.1 & 40.1 & 40.1 & 40.1 & 40.1 & 40.1 & 40.1 & 40.1 \\
\hline L.C.L & 39.9 & 39.9 & 39.9 & 39.9 & 39.9 & 39.9 & 39.9 & 39.9 & 39.9 & 39.9 & 39.9 & 39.9 & 39.9 & 39.9 & 39.9 \\
\hline U.S.L & 40.2 & 40.2 & 40.2 & 40.2 & 40.2 & 40.2 & 40.2 & 40.2 & 40.2 & 40.2 & 40.2 & 40.2 & 40.2 & 40.2 & 40.2 \\
\hline L.S.L & 39.8 & 39.8 & 39.8 & 39.8 & 39.8 & 39.8 & 39.8 & 39.8 & 39.8 & 39.8 & 39.8 & 39.8 & 39.8 & 39.8 & 39.8 \\
\hline average & 40 & 40 & 40 & 40 & 40 & 40 & 40 & 40 & 40 & 40 & 40 & 40 & 40 & 40 & 40 \\
\hline
\end{tabular}

Table 3. Scatter diagram (relation between Cracks side and temperature).

\begin{tabular}{|c|c|c|c|c|c|c|c|c|c|c|c|c|c|c|}
\hline Day & 1 & 2 & 3 & 4 & 5 & 6 & 7 & 8 & 9 & 10 & 11 & 12 & 13 & 14 \\
\hline Cracks side & 332 & 450 & 344 & 460 & 356 & 91 & 140 & 110 & 112 & 120 & 115 & 121 & 122 & 110 \\
\hline Temperature $\left({ }^{\circ} \mathrm{C}\right)$ & 35 & 34 & 35 & 35 & 31 & 33 & 34 & 35 & 37 & 40 & 39 & 42 & 35 & 33 \\
\hline
\end{tabular}

\section{Conclusions}

This study distinguished that it is very essential to apply all the seven QC tools for investigating issues within production processes in the organizations. Without a shadow of doubt, all of the previously mentioned quality tools should be considered and used by management for identifying and solving quality problems amid producing the products and services.

Along these lines, the production processes can be influenced and improved by multiple factors of these statistical QC tools. In this study case, The Check Sheet clarifies the Cracks sides were the most repeated defects as they happened 4851 times, and then they are followed by the Dimension error which was repeated 2242 times. With a specific end goal to be effectively utilized, the Histogram has to be appropriately and professionally designed. Moreover, Pareto diagram identifies that Cracks side and Dimension error are the vital view defects that need attention. Fishbone Diagram shows the categories of the cause, which are the main causes of cracks side defect, such as environment, labors, equipment and materials. The Control Charts indicate the Dimension error defects and show the points which are in and out of control. Control Charts are among the most effective management control tools, and they are as important as cost 
control and material control. Graphically, this confirms variation in output quality characteristics against pre-fixed upper and lower limits. Flowchart shows the process from start to end and the process will be stopped due to any product defect. Finally, Scatter Diagram proves that there is no direct relationship between Cracks side defects and temperature during different production stages. These tools are helpful at every stage of the defect removal process. As a result, the main objectives of this research were achieved. The successful application of the seven basic quality control tools in the construction industry was investigated and the level of quality in the construction industry using these tools was improved.

\section{Conflicts of Interest}

The authors declare no conflicts of interest regarding the publication of this paper.

\section{References}

[1] ISO (2008) ISO 9001:2008. Quality Management Systems. Requirements.

[2] Mandavgade, N.K. and Jaju, S.B. (2009) Optimization of Cost by Using 7 QC Tools. International Journal of Engineering Studies, 1, 149-160.

[3] Jha, M., Tyagi, R.K. and Gupta, G. (2013) Reduction of Rejected Components in an Automobile Assembly Line Using Quality Tools. European Journal of Applied Engineering and Scientific Research and Technology, 2, 13-17.

[4] Fouad, H.K. and Mukattash, A. (2010) Statistical Process Control: A Practical Guide for Jordanian Industrial Organizations. Jordan Journal of Mechanical and Industrial Engineering, 4, 693-700.

[5] Omachonu, V.K. and Ross, J.E. (2004) Principles of Total Quality. 3rd Edition.

[6] Montgomery, D.C. (2009) Introduction to Statistical Quality Control. 6th Edition, John Wiley \& Sons, Inc., Danvers.

[7] Forbes, L.H. and Ahmed, S.M. (2011) Modern Construction: Lean Project Delivery and Integrated Practices. Taylor and Francis Group, Boca Raton. https://doi.org/10.1201/b10260

[8] Juran, M. and Godfrey, A. (1998) Juran's Quality Handbook. 5th Edition, McGraw-Hill Companies, Inc., Washington DC.

[9] Kerzner, H. (2009) Project Management: A Systems Approach to Planning, Scheduling, and Controlling. 10th Edition, John Wiley \& Sons, Inc., Hoboken.

[10] Neyestani, B. (2017) Principles and Contributions of Total Quality Management (TQM). Gurus on Business Quality Improvement.

[11] Oakland, J.S. (2003) Total Quality Management: Text with Cases. 3rd Edition, Butterworth-Heinemann, Oxford. 